Journal Article

\title{
Composite repairs to bridge steels demystified
}

Ali, K., Singh Raman, R.K., Zhao, X.L., Jones, R., McMillan, A.J.

This article is published by Elsevier. The definitive version of this article is available at:

http://www.sciencedirect.com/science/article/pii/S0263822316312569?via\%3Dihub

\section{Recommended citation:}

Ali, K., Singh Raman, R.K., Zhao, X.L., Jones, R., McMillan, A.J. (2017), 'Composite repairs to bridge steels demystified', Composite Structures, vol 169, pp. 180-189. doi: 10.1016/j.compstruct.2016.07.049. 


\title{
COMPOSITE REPAIRS TO BRIDGE STEELS DEMYSTIFIED
}

\author{
K. Ali ${ }^{1}$, R.K. Singh Raman ${ }^{1}$, X.L. Zhao ${ }^{2}$, R. Jones ${ }^{1}$ and A. J. McMillan ${ }^{3}$ \\ 1Department of Mechanical and Aerospace Engineering, Monash University, Clayton, Vic \\ 3800, Australia.
}

2Department of Civil Engineering, Monash University, Clayton, Vic 3800, Australia.
${ }^{3}$ Department of Engineering and Applied Physics, Glyndwr University, Wrexham, LL11 2AW, Wales, UK.

\begin{abstract}
This paper examines crack growth associated with carbon fibre reinforced plastic (CFRP) repairs to cracked bridge steels and boron epoxy composite and fibre metal patch repairs to cracked aluminium alloy structures. It is first shown that the da/dN versus $\Delta K$ curves associated with bridge steels is very similar to that seen in the high strength aerospace steel D6ac. The importance of $1^{\text {st }}$ ply failure, which was first observed on a boron epoxy repair to the F-111 D6ac steel wing pivot fitting, and how to alleviate this failure mechanism is then discussed as is the common design approach whereby after patching the repair is designed to have a $\Delta K$ beneath the ASTM long crack threshold $\Delta K_{\text {th. }}$. It is shown that crack growth in bridge steels repaired with CFRP patches and in aluminium alloy structures repaired with either boron epoxy or glare patches exhibit a near linear relationship between the log of the crack length and the number of cycles. We then show that crack growth in these repairs can be represented by the same simple master curve relationship that has been found to hold for cracks growing in both operational aircraft and full scale fatigue tests. These findings are important since they suggest that the methodology used by the Royal Australian Air Force to certify structural modifications to operational aircraft may also be applicable to composite repairs/modifications to steel bridges, which are generally experience significantly lower stresses.
\end{abstract}

Keywords: Aging bridges; composite repairs; fatigue crack growth; fractals; ASTM E647-13a;

\section{INTRODUCTION}

It is now known $[1,2]$ that the fatigue life of operational aircraft is governed by the growth of lead cracks, i.e. the fastest cracks in the structure, that have the following characteristics, from [1], viz:

i. Typical initial discontinuity sizes are about equivalent to a $0.01 \mathrm{~mm}$ deep fatigue crack.

ii. They start to grow shortly after the aircraft is introduced into service.

iii. The majority of the life is consumed growing to a size that can be detected using existing non destructive inspection techniques.

The US Federal Highway Administration Steel Bridge Design Handbook [3] makes similar statements, viz: 
a) ".. it is inevitable that cracks or crack-like discontinuities will be present in fabricated steel elements. Thus, the engineer is responsible to consider the consequences of potential fatigue and subsequent brittle fracture. The fatigue behavior of a fabricated steel structure is controlled by the presence of pre-existing cracks or crack-like discontinuities, which most often occur at welded connections or other areas of stress concentrations. Consequently, there is little or no time during the life of the structure that is taken up with "initiating" cracks."

b) "Experience in the laboratory shows that as much as $80 \%$ of the fatigue life has been consumed by the time a fatigue crack emanating from an internal flaw reaches the surface and can be observed."

The similarity associated with cracking in bridges and cracking in aircraft is reinforced in Figures 1 and 2 which shows cracking in a bridge section and cracking in the D6ac steel wing pivot fitting in the 1969 General Dynamics, now Lockheed, F-111 wing fatigue tested under a representative F-111 usage spectrum ${ }^{1}$ respectively. Both figures show how cracking grew from small sub $\mathrm{mm}$ material discontinuities.

Of particular interest is the fact that the $\mathrm{da} / \mathrm{dN}$ versus $\Delta K$ curves for bridge steels are similar to that of the high strength aerospace steel D6ac steel. To illustrate this Figure 3 presents the $\mathrm{da} / \mathrm{dN}$ versus $\Delta \mathrm{K}$ relationship suggested by the Japan Society of Steel Construction (JSSC) [7], viz:

$$
\mathrm{da} / \mathrm{dN}=1.5 \times 10^{-11}(\Delta \mathrm{K})^{2.75}
$$

and the $d a / d N$ versus $\Delta K$ relationship suggested in [8], viz:

$$
\mathrm{da} / \mathrm{dN}=6.86 \times 10^{-12}(\Delta \mathrm{K})^{3}
$$

together with the da/dN versus $\Delta K$ curves presented in [9] for D6ac steel tested at $R$ values that ranged from 0.1 to 0.9 .

Here we see that, allowing for experimental error, the da/dN versus $\Delta \mathrm{K}$ relationship suggested by the Japan Society of Steel Construction (JSSC) and by Barsom and Rolfe for bridge steels are similar and essentially coincide with the experimental data associated with D6ac steel. Furthermore, the da/dN versus $\Delta K$ is essentially $R$ ratio independent, as are both equations (1) and (2). The lack of an $R$ ratio dependency means that there is no crack closure and hence that crack growth in bridge steels should not be modelled using crack closure based crack growth equations.

\subsection{First ply failure}

The similarity between crack growth in bridge steels and operational aircraft coupled with the similarity seen in the crack growth behaviour of bridges steels and D6ac steel is particularly interesting since the origin of the application of bonded carbon fibre reinforced polymers (CFRP)

\footnotetext{
${ }^{1}$ This example was chosen since the in-flight failure of a F-111 was largely responsible for the USAF adopting a damage tolerance approach [6].
} 
to repair/rehabilitate civil infrastructure can be traced back to the use of bonded patches to repair military aircraft [10-16]. In this context the ability of an eternally bonded composite repair ${ }^{2}$ to successfully reduce the strain in the highly loaded ${ }^{3}$ D6ac steel wing pivot fitting by approximately $30 \%$ [11], the steel wing pivot fitting transmitted the flight loads through to the carry through box, was one of the early papers that highlighted the potential for bonded composite repairs to repair/rehabilitate steel bridges which are generally subjected to far lower loads. During the operational life of the aircraft twenty aircraft (i.e. thirty eight wings with a total of seventy six doublers, there are two doublers per wing) were successfully proof loaded in the US and a further two wings passed a proof load test in Australia [14]. This led to an enunciation of the failure mechanisms for bonded composite joints and repairs to both civil infra-structure and military $[15,16,17]$ and civil transport aircraft $[19]$ and to the development of validated design criteria for composite repairs $[17,18,19]$.

Figure 4 presents a typical failure surface associated with boron epoxy repairs to aluminium structures, from [15]. Whilst the propensity of composite joints to fail due to cohesive delamination had been known [20] this failure mechanism, which involves interfacial disbonding between the adhesive and the patch followed by final failure in the composite due to delamination of the upper 9 plies from the (1st) ply next to the adhesive boron interface, was first explained in [15]. This " 1 st ply failure" mechanism was also seen in the boron epoxy repair to the F-111 wing pivot fitting, see Figure 5, and is reported in [21, 22].

This 1st ply failure mechanism is also visible in the failures shown in $[23,24]$ in CFRP bonded repairs (to bridge steels) and joints. It is a combination of failure mode (c) and failure mode (d) shown in the schematic diagram given in [23], and reproduced in Figure 6. As such one aspect of the present paper is to stress the potential for 1st ply failure to occur in both CFRP and boron epoxy repairs and metal to composite joints.

Fortunately as exemplified by the doubler modifications adopted following an early F-111 failure the use of a thin interleaf adhesive, in this particular instance a $0.025 \mathrm{~mm}$ thick layer of FM3002 , between the $1^{\text {st }}$ and the $2^{\text {nd }}$ plies, can be used to both toughen the matrix material and also reduce the local interlaminar stresses and thereby largely overcome this failure mechanism, see $[13,25]$ for more details. As such the use of a thin interleaf layer between the $1^{\text {st }}$ and $2^{\text {nd }}$ plies of the composite doubler is recommended for all composite repairs.

\subsection{Experimental test and analysis requirements for CFRP repairs to operational structures}

The effect that elevated temperatures and the environment, including the effect of combined temperature and moisture, have on both the static strength and the fatigue life of composite repairs was documented in [22]. This study, which reinforced the role that $1^{\text {st }}$ ply failure plays in composite repairs, concluded:

"The fracture paths in this bonded system indicated that the environment appeared to have affected the adhesive and/or composite matrix materials to a greater extent than the adhesiveadherend interfaces. Additionally, the crack growth rate sensitivity of this bonded metal-

\footnotetext{
${ }^{2}$ These doublers were approximately 120 plies thick and took approximately $30 \%$ of the load in the critical section of the wing pivot fitting

${ }^{3}$ The magnitude of the load carried by the wing pivot fitting was such that the critical region experienced strains in excess of $26,000 \mu \varepsilon$
} 
composite system far exceeded that of metals. Though unaffected by long-term environmental exposure, this high sensitivity suggests that continued operation of bonded structures below the identified threshold is necessary to avoid unanticipated rapid Mode I crack growth."

In the tests described in [22] hot/wet exposure for 5,000 hours resulted a reduction in the load carrying capacity of up to $50 \%$. This study led to the realisation that a hot/wet environment can adversely affect the adhesive and/or the composite matrix rather than the metal-adhesive interface. Similar findings have also been reported for CFRP to steel joints/repairs [26].

However, with respect to the design approach proposed in [22], i.e. that repairs should be designed such that after patching $\Delta K$ is beneath its (long crack) threshold value it is explained in Appendix X3 of the ASTM fatigue test standard E647-13a that for cracks that occur in operational structures the fatigue threshold is very low. Indeed, E647-13a Appendix questions if a threshold exists.

As such the conclusion stated in [22], and repeated above, reflects a common misunderstanding in the nature of the tests needed to assess the effect of composite repairs to operational structures, albeit either aerospace or civil infrastructure. This is because, as stated in ASTM E64713a, even if the value of $\Delta K$ is beneath its (long crack) threshold value it may not be beneath the threshold that will be seen in the structure. This is because, unlike long cracks, naturally occurring cracks have a very small fatigue threshold which can be expected to be significantly smaller than the corresponding long crack threshold.

Until recently tests used to assess the effectiveness of composite repairs used specimens where the repairs were applied to long cracks that were generated using ASTM like specimens, viz: centre notch panels or edge cracked specimens with initial cracks that were grown from artificial initial notches. As explained above and in ASTM E647-13a and [27] such specimens yield a da/dN versus $\Delta K$ curve that has a sigmoidal shape with a well defined fatigue threshold $\Delta \mathrm{K}_{\mathrm{th}}$. As such when such specimens are repaired with a composite patch then if the value of $\Delta \mathrm{K}$ after patching is less than $\Delta K_{\text {th }}$ for the specimen then crack growth is stopped. However, as explained above and in Appendix X3 of ASTM E647-13a and also in [27] for cracks that have arisen and grown naturally in operational structures the threshold is dramatically lower that the $\Delta K_{\text {th }}$ for such (long crack) specimens. As such even though when a patch is applied to a relatively long crack in an operational structure the stress intensity factor (after patching) is greatly reduced it can still be greater than the actual threshold value that is seen in the real (operational) structure. Hence, even though the laboratory test (on a repaired ASTM like specimen) would suggest that the patch would stop crack growth when the patch is applied to the real structure crack growth can nevertheless occur. (Here it should be recalled that, as mentioned above, E647-13a questions whether a threshold exists for cracks that arise and grow naturally in operational structures.) As such, as first explained in [27], if laboratory tests are to be performed to evaluate the effect of composite patches to an operational structure, i.e. to a steel bridge, then it is essential that, in these tests, the cracks are first allowed to developed naturally and then patched/repaired. One means of achieving this is to grow cracks from small etch pits [28], another way is to use lasers to create small near micron size initial notches $[29,30]$.

Unfortunately this realisation means that whilst most of the studies conducted to date on composite repairs are very valuable in that they highlight the benefit that can be obtained using composite repairs such tests should not be used to assess the effect of the repair on an operational structure (aircraft/bridge). 
It should nevertheless be stressed that patches designed in this fashion can often dramatically retard crack growth. Indeed the results of the boron epoxy repairs to the Mirage III [31], where the patch reduced the stress intensity factor by more than $90 \%{ }^{4}$ [32] and hence was indeed beneath the long crack threshold, and the C-141 repair program [33] show that such repair designs can be very effective. However, as noted in ASTM 647-13a any analysis/design (repair assessment) of a composite repair to an operational structure should use valid da/dN versus $\Delta K$ small crack data. This is particularly important since as explained in $[34,35]$ even for materials that, for long cracks, exhibit crack closure effects the small crack da/dN versus $\Delta K$ curve is essentially $R$ ratio and crack closure free. Hence, crack closure based analysis of CFRP repairs to bridge steels, which as we have seen above exhibit little crack closure even if the crack is long, is inapplicable ${ }^{5}$. At this stage it should be reiterated that, it also follows that since the da/dN versus $\Delta K$ curves associated with ASTM like specimen tests and specimens in which the crack has grown from a small naturally occurring material discontinuity differ, and hence the fatigue thresholds $\Delta \mathrm{K}_{\text {th }}$ differ markedly, the certification test program should use specimens where prior to patching the crack(s) are grown from small initial material discontinuities.

\subsection{Exponential crack growth}

Following the development of composite repair technology it was subsequently found [1, 38-41] that cracks that grow in operational aircraft and in full scale fatigue tests and cracks growing beneath composite repairs often exhibit a (near) linear relationship between the log of the crack length and the number of cycles ${ }^{6}$ which can be expressed in the form, viz:

$$
a=a_{0} e^{\varpi N}
$$

where $\mathrm{N}$ is the number of cycles, $\mathrm{a}_{0}$ is the initial flaw-like size, and $\varpi$ is a parameter that is both geometry and load dependent. For aluminium alloys, titanium and steels $[40,41,43,44] \varpi$ can frequently be expressed in the form:

$$
\varpi=\Psi(\Delta \sigma)^{3}
$$

where $\Psi$ is load spectrum dependent. Indeed, this cubic dependence of the crack growth rate on the stress is incorporated in the US AASHTO bridge design standards [45, 46]. This loglinear formulation together with the cubic stress dependency forms part of the certification basis for RAAF F/A-18 (Hornet), P3C (Orion) aircraft and PC9 trainer aircraft $[1,41,47,48]$. The physical reason for this ${ }^{7}$ formulation is that, as explained in $[49,50]$, the growth of cracks that initiate from small naturally occurring material discontinuities behave, as explained by Mandelbrot ${ }^{8}[51]$, as a fractal and have a fractal box dimension (D) of approximately 1.2 [51,

\footnotetext{
${ }^{4}$ Nevertheless limited crack growth was observed in operational aircraft.

${ }^{5}$ Here it should be noted that it is now know that for a range of materials tested under a range of operational load spectra the growth of cracks that initiate and grow from small naturally occurring material discontinuities can be accurately computed using the $\mathrm{R}$ ratio independent $\mathrm{da} / \mathrm{dN}$ versus $\Delta \mathrm{K}$ small crack relationship and setting closure effects to zero [27, 28, 34-37].

${ }^{6}$ This is also referred to as exponential crack growth.

${ }^{7}$ In the case of cracks that arise and grow from small sub $\mathrm{mm}$ material discontinuities. ${ }^{8} \mathrm{An}$ interview with Professor Mandlebrot where he gives an explanation of fractals and roughness is available on line at: https://www.youtube.com/watch?v=Xm-2ouPGrlY
} 
52]. The fact that this value of the fractal box dimension $D(=1.2)$ holds for a large crossection of materials is documented in $[49,53]$.

As mentioned above $[38,39]$ revealed that cracks in aluminium structures repaired with a composite patch also exhibit a near linear relationship between the log of the crack length and the number of cycles. This is evident in Figures 7 and 8 which present crack growth curves for a 2024-T3 specimen patched using a seven ply boron epoxy laminate, see [38, 39] for more details. Figure 8 also contains the crack growth history predicted in $[38,39]$ for the $160 \mathrm{MPa}$ test using the $80 \mathrm{MPa}$ test crack growth history and equations (3) and (4).

Reference [39] also revealed that the data given by Guijt et al [56] which studied the behaviour of boron epoxy and glare (a fibre metal laminate) patches to a $4 \mathrm{~mm}$ thick centre cracked 7075-T6 aluminum panel also exhibited a cubic stress dependency. In this test the panels were $180 \mathrm{~mm}$ wide and $600 \mathrm{~mm}$ long and contained a centrally loacated center crack with an initial $25 \mathrm{~mm}$ long fatigue crack. Single sided patches $75 \mathrm{~mm}$ wide and $190 \mathrm{~mm}$ long were applied to all panels. The panels were tested under constant amplitude loading with $\sigma_{\max }=120 \mathrm{MPa}$ and $\sigma_{\min }=6 \mathrm{MPa}$. The results are presented in Figure 9 where we also see a near log-linear relationship. Reference [39] also revealed that this relationship also held for patched cracks growing under representative flight load spectra.

Guijt and Verhoeven [57] presented results for a simulated C-5A repair using Glare 2 patches on a 7075-T6 aluminium alloy panel tested under a C5A flight load spectrum. The resultant crack growth histories are presented in Figure 10, where we again see a near log linear relationship.

\subsection{A master curve representation for crack growth in operational structures}

The 2014 review paper [34] explained that cracks that grow from small naturally occurring material discontinuities under either constant amplitude or representative flight load spectra can be represented by a single master curve regardless of the nature of the spectrum or the material ${ }^{9,10}$, viz:

$$
\left(N-N_{i}\right) /\left(N_{f}-N_{i}\right)=1-\ln \left(a / a_{f}\right) / \ln \left(a_{i} / a_{f}\right) \quad(=\phi(a))
$$

Here $a_{i}$ and $a_{f}$ are the initial and final crack sizes, $N_{i}$ and $N_{f}$ are the corresponding number of cycles, and $\mathrm{N}$ is the number of cycles required to reach a crack length " $a$ ". As noted in [34] as the crack size approaches its critical length we need to account for $\mathrm{K}_{\max }$ approaching its fracture toughness. However, this effect often tends to be small and, as shown in [34], generally only affects the region $\mathrm{a} / \mathrm{a}_{\mathrm{f}}>0.75$. A similar deviation from equation (5) occurs as the crack length approaches the initial discontinuity size. As a result the slope of the $\left(N-N_{i}\right) /\left(N_{f}-N_{i}\right)$ versus $\phi(a)\left(=1-\ln \left(a_{/} / a_{f}\right) / \ln \left(a_{i} / a_{f}\right)\right)$ curves sometimes differs slightly from that suggested by equation (5).

This "master curve" representation was shown to hold for a wide range of materials. It was subsequently also shown to hold for cracks growing in both operational aircraft

\footnotetext{
${ }^{9}$ This observation is also true for the growth of large cracks in centre cracked (middle tension) panels [34].

${ }^{10}$ It follows from $[49,50]$ that this behaviour is due to the value of the fractal box dimension (D) associated with the growth of small naturally occurring cracks $[52,53]$.
} 
and in full scale fatigue tests under representative operational load spectra [36], see Figure 11. Nevertheless, as shown in [27, 28], this approach predicts that, for tests on centre cracked panels and surface and edge cracks under repeated block loading, for the majority of the fatigue life we should see a near linear relationship between the number of load blocks and the log of the crack length. Furthermore, equation (5) also predicts that this relationship should hold regardless of the material or the nature of the spectra. The accuracy of this prediction ${ }^{11}$ is illustrated in both $[27,28]$ and is shown in Figure 11, see [28] for more details.

In this paper we will first show that crack growth in centre or edge cracked bridge steels specimens repaired with normal modulus, high modulus or ultra-high modulus (UHM) CFRP patches also has a near linear relationship between the log of the crack length and the number of cycles. We then show that crack growth in patched centre or edge cracked specimens can also be represented by the simple master curve relationship given in equation (5) regardless of whether we are considering aluminium alloy structures repaired with a boron epoxy or a glare patch or bridge steels repaired with normal modulus, high modulus or ultra-high modulus (UHM) CFRP patches.

These findings are important since, when taken in conjunction with the fact that cracking in steel bridges has several similarities to cracking in operational aircraft, they suggest that the methodology used by the Royal Australian Air Force to certify structural modifications to operational aircraft, which are based on the observation that crack growth in operational aircraft is near log-linear and that crack growth is proportional to the cube of the stress, may also be useful for assessing the effect of composite repairs/modifications to steel bridges, see Appendix.

\section{CRACK GROWTH IN STEEL STRUCTURES REPAIRED WITH CFRP PATCHES}

The 2013 report [58] by Transportation for America, which summarized a detailed analysis of the US National Bridge Inventory (a database produced by the Federal Highway Administration (FHWA), found that one in nine U.S. bridges had been rated "structurally deficient." To put the problem into perspective [58] commented that, in the USA, there are more trips per day over structurally deficient bridges than there are McDonald's hamburgers eaten in the entire USA. This problem has led to an interest in the ability of CFRP to strengthen steel infrastructure. The use of CFRP to strengthen Melbourne (Australia's) Westgate bridge [59] is an excellent example of the practical use of this technology.

In this context let us examine the effect of CFRP repairs to crack growth in centre or edge cracked bridge steel specimens. Although the log-linear relationship was first observed for boron epoxy and glare composite repairs to aluminium aerospace structures it also appears to hold for CFRP repairs to bridge steels. To illustrate first consider the crack growth data presented in [60]. The (bridge) steel plate had a $10 \mathrm{~mm}$ diameter hole in a $90 \mathrm{~mm}$ wide plate. The hole contained two diametrically opposed $1 \mathrm{~mm}$ initial notches that lay on the centre line of the plate. Figure 12 contains the results obtained for the patch configurations shown in Table 1. This study used both MBRACE normal modulus and high modulus CFRP. The Young's modulus of the "normal" CFRP was 230,000 MPa and 552,000 MPa for the high modulus CFRP. The thicknesses associated with these two different sheets (patches) were $4.2 \mathrm{~mm}$ and 4.5

\footnotetext{
${ }^{11}$ Since this figure is for spectrum loading B is the number of load blocks rather than cycles or flight hours.
} 
$\mathrm{mm}$ respectively. The Young's modulus of the (bridge) steel plate was $200,000 \mathrm{MPa}$ and its thickness was $10 \mathrm{~mm}$.

As an aside Figure 12 also contains the predicted crack growth history for specimen test DN5B250 using equation (3) and the value of $\varpi(=1.381)$ associated with specimen test DH5B100 together with equation (4) and the stress ratio (in the steel) associated with these two different CFRP patches. In the notation used in [60] the symbol $\mathrm{N}$ denotes specimens repaired with normal modulus CFRP and the symbol $\mathrm{H}$ denotes specimens repaired with high modulus CFRP. The notation DNB, DHB refers to specimens that are patched on both sides with normal and high modulus CFRP the notation B to the geometry of the patch used, see Table 1. Similarly the notation DND, DHD refers to specimens that are patched on both sides with normal and high modulus CFRP and the notation D to the geometry of the patch used, see Table 1 . The notation 100 or 250 refers to the length of the patch. Thus specimen DH5D250 was patched on both sides with five layers of high modulus CFRP. The CFRP was 250 $\mathrm{mm}$ long and the geometry of the patch was as per case $\mathrm{D}$. On the other hand specimen DH5C250 was patched on both sides with five layers of high modulus CFRP. The CFRP was $250 \mathrm{~mm}$ long and the geometry of the patch was as per case $C$, see [60] for more details.

Next consider the crack growth data given in Figure 13 in [61], which used ultra-high modulus CFRP (a $1.5 \mathrm{~mm}$ thick MBRACE laminate $460 / 150$ with a primary Young's modulus of 460000 MPa Young's modulus) to repair a $10 \mathrm{~mm}$ thick (bridge) steel plate where the steel had an ultimate tensile strength of $530 \mathrm{MPa}$ and a Youngs modulus of $200 \mathrm{MPa}$. Figure 13, in [22], also included data from [62] which used CFRP sheeting. Both data sets are replotted in Figure 13. In each case we see that crack growth in bridge steels patched with CFRP exhibits a near linear relationship between $\ln (a)$ and the number of cycles. It thus appears that this log-linear relationship holds for aluminium panels repaired with either boron epoxy or glare patches or bridge steels repaired with ultra-high, normal, or high modulus CFRP patches.

Reference [63] also presents crack growth data for centre cracked panels repaired using a 1.4 mm thick "normal" modulus CFRP (MBRACE Laminate 210/3300) which had a modulus of 210 $\mathrm{MPa}$ to repair a $10 \mathrm{~mm}$ thick steel plate which had a Young's modulus of $200 \mathrm{MPa}$. The crack growth data for different initial damage states, viz: 2, 10, and 20\%, which were defined in [63] as the ratio of the initial crack to the width of the specimen, are shown replotted in Figure 14. Here we again see a near linear relationship between $\ln (a)$ and the number of cycles.

To continue this study consider the crack growth data presented in [64] which tested edge cracked steel beams that were reinforced using pultruded CFRP doublers. The pultruded CFRP doublers (Sika CarboDur M614) had a width of $60 \mathrm{~mm}$ and a length of $800 \mathrm{~mm}$. Test specimen B03 had a $1.4 \mathrm{~mm}$ thick CFRP doubler, specimen tests B06, B07, B08 and B09 used $2.8 \mathrm{~mm}$ thick CFRP doublers. The resultant crack length versus cycles curves are shown in Figure 15 where we again see a near linear relationship between $\ln (a)$ and the number of cycles.

Next consider the crack growth data presented in [65] for a $700 \mathrm{~mm}$ long, $100 \mathrm{~mm}$ wide, and $10 \mathrm{~mm}$ thick edge-cracked steel plate patched with a $1.4 \mathrm{~mm}$ thick full width CFRP plate with a primary Youngs modulus of $165 \mathrm{MPa}$. In [65] this specimen is designated specimen E1. The resultant crack length history is shown in Figure 16 where we again see a near linear relationship between $\operatorname{In}(a)$ and the number of cycles. 
The universal nature of the value of the fractal box dimension (i.e. a value of $\mathrm{D} \sim 1.2$ regardless of the material) coupled with the similarity seen for crack growth in bridge sections and in the 1969 F-11 wing test, see Figures 1 and 2, plus the similarity seen in the da/dN versus $\Delta \mathrm{K}$ curves for D6ac steel and bridge steels, see Figure 3, and the near log-linear crack growth curves seen in Figures 7-10 and Figures 12-16 suggests that the master curve concept discussed above may also apply to composite repairs to both aircraft and bridge steels. To evaluate this concept Figure 17 presents a graph of $\varphi(a)$ $\left(=1-\ln \left(\mathrm{a}_{/} \mathrm{a}_{\mathrm{f}}\right) / \ln \left(\mathrm{a}_{\mathrm{i}} / \mathrm{a}_{\mathrm{f}}\right)\right)$ against $\left(\mathrm{N}-\mathrm{N}_{\mathrm{i}}\right) /\left(\mathrm{N}_{\mathrm{f}}-\mathrm{N}_{\mathrm{i}}\right)$ for the CFRP bridge steel patched results presented in Figures 12 - 16 together with the patched panel test results given in Figures 7-10. The associated values of $\mathrm{a}_{\mathrm{i}}, \mathrm{a}_{\mathrm{f}}$ and $\mathrm{N}_{\mathrm{i}}, \mathrm{N}_{\mathrm{f}}$ are given in Table 2 . Here we see that, allowing for experimental error, the various experimental data sets discussed above do indeed (approximately) conform to this Master Curve regardless of the material, patch or adhesive type.

\section{CONCLUSION}

This paper first reveals the similarities between crack growth in aircraft and in bridge steels. It then highlights the role that $1^{\text {st }}$ ply failure can play in composite repairs and how the results of the F-111 doubler repair program suggests that this particular failure mechanism can largely be suppressed by using a thin interleaf adhesive between the $1^{\text {st }}$ and $2^{\text {nd }}$ plies. It has also been mentioned that temperature-environment effects tend to degrade the adhesive composite interface rather than the bond to the metal.

Whilst it had previously been thought that tests on ASTM E647 like test specimens with long cracks that have been grown from artificial notches could be used to assess composite repairs to operational structures this paper explains that this can't be assumed to be true. As a result when designing composite repairs to operational structures the test used to investigate/validate these designs should be on specimens where, prior to patching, the cracks have initiated and subsequently grown from small naturally occurring material discontinuities, for example small initial pits, and then patched once the crack has reached a required length.

It is further shown that analyses of repairs to cracks that have initiated and grown from small naturally occurring material discontinuities in operational structures should use valid small crack da/dN versus $\Delta K$ data. Such data is invariably (essentially) $R$ ratio independent. In this context it has been shown that crack growth in bridge steels resembles that seen in the high strength aerospace steel D6ac and that the experimental data reveals that the associated $\mathrm{da} / \mathrm{dN}$ versus $\Delta \mathrm{K}$ curves are essentially $\mathrm{R}$ ratio independent and hence experience little, if any, crack closure. This means that the use of crack closure based concepts to compute the growth of cracks in CFRP repaired bridge steels is inappropriate.

It is also shown that the experimental data presented reveals that crack growth in centre and edge cracked bridge steels repaired with CFRP patches behaves like crack growth in boron epoxy repairs and glare repairs to cracked aerospace quality aluminium alloy structures in that there is a near linear relationship between the log of the crack length and the number of cycles. We also show that crack growth in bridge steels repaired with CFRP patches can be represented by the same simple master curve relationship that has been found to hold for cracks growing in operational aircraft and in full scale fatigue tests. This master curve 
relationship is also shown to hold for aerospace quality aluminium alloy structures repaired with boron epoxy and glare patches.

These new findings are important since they suggest that the methodology used by the Royal Australian Air Force to certify structural modifications to a range of operational aircraft, which is based on the observation that growth of lead cracks in operational aircraft is essentially loglinear and that that crack growth is proportional to the cube of the stress, may also be useful for assessing the effect of composite repairs/modifications to steel bridges which generally experience significantly lower stresses. As shown in the Appendix this approach is attractive in that if data is available on the crack growth history prior to patching then the effect of a CFRP repair on crack growth and the remaining life of the section can be estimated without a knowledge of the operational load history and without the need to use a fracture mechanics based crack growth analysis.

\section{ACKNOWLEDGEMENT}

The authors gratefully acknowledge the financial support provided by the Australian Research Council through an ARC Discovery Grant (DP120101708).

\section{REFERENCES}

1. Barter SA., Molent L., Wanhill RH., The lead crack lifing framework, International Journal of Fatigue, 41, pp. 1-198, 2012.

2. Dixon B., Molent L., Barter S., A study of fatigue variability in aluminium alloy 7050-T7451, International Journal of Fatigue 92, pp. 130-146, 2016.

3. Mertz D., Steel Bridge Design Handbook: Design for Fatigue, U.S. Department of Transportation, Federal Highway Administration, Publication No. FHWA-IF12-052 - Vol. 12, November 2012.

4. Dexter RJ., and Ocel JM., Manual for Repair and Retrofit of Fatigue Cracks in Steel Bridges, US Department of Transportation, Federal Highway

Administration Report FHWA-IF-13-020, March 2013.

5. Murtagh BJ., Walker KF., Comparison of analytical crack growth modelling and the A-4 wing test experimental results for a fatigue crack in an F-111 wing pivot fitting fuel flow hole number 58, Aeronautical and Maritime Research Laboratory Technical Note DSTO-TN-0108, September 1997.

6. Tiffany CF., Gallagher JP., Babish IV CA. (2010) Threats to aircraft structural safety, including a compendium of selected structural accidents/incidents, Aeronautical Systems Center, Engineering Directorate, Wright-Patterson Air Force Base, ASC- TR-2010-5002.

7. Japan Society of Steel Construction (JSSC), Fatigue design recommendations for steel structures, 1995.

8. Barsom, J. M., and Rolfe, S. T. (1999) Fracture and fatigue control in structures: Applications of fracture mechanics, 3rd Ed., ASTM MNL41, ASTM, West Conshohocken, PA.

9. Forth SC., James MA., Newman JA. Everett, RA. Jr., and Johnston WM. Jr. (2004) Mechanical data for use in damage tolerance analyses, NASA/TM-2004213503 and ARL-TR-3375.

10. Jones R., et al, Application of B.F.R.P. patching to Mirage III Aircraft, Proceedings of the 3rd International Conference on Composite Materials, Paris, 
France, August 1981. Vol. 11, pp. 1424-1438, 1980, Theoretical and Applied Fracture Mechanics, 2, 1, pp. 1-16 1984.

11. Molent L, Callinan RJ. and Jones R., Design of an all boron epoxy doubler for the F-111C wing pivot fitting: Structural Aspects, Composite Structures, 11, 1, pp. 57-83, 1989.

12. Baker A. and Jones R., , Bonded Repair of Aircraft Structure, Martinus Nijhoff Publishers, The Hague, 1988. (Book),

13. Jones R and Molent L., Application of constitutive modelling and advanced repair technology to F111C aircraft, J. Composite Structures, 66, pp. 145-157, 2004.

14. Chalkley P. and Geddes R., Service History of the F-111 Wing Pivot Fitting Upper Surface Boron/Epoxy Doublers, DSTO-TN-0168, Department of Defence, September 1998.

15. Jones R., Chiu WK. and Hanna S., Potential failure mechanisms of bonded composite repairs for metal and concrete, Theoretical and Applied Fracture Mechanics, 21, pp. 107-119, 1994.

16. Jones R. and Smith R., Continued Airworthiness Of Composite Repairs To Primary Structures For Military Aircraft, Journal of Composite Structures, 33, pp. 17-26, 1995.

17. Jones R, Numerical Analysis and Design, Chapter 9, A. Baker, L. R. F. Rose and Jones R., Elsevier Applied Science Publishers, 2002. ISBN 0-08-042699-9.

18. Chiu WK., Rees D., Chalkley P. and Jones R., Designing for damage tolerant repairs, Journal of Composite Structures, 28, 1, pp. 19-38, 1994.

19. Roach, D.P., "Damage Tolerance Assessment of Bonded Composite Doubler Repairs for Commercial Aircraft Applications," Sandia National Laboratories/ Dept. of Energy Report No. SAND98-1016, August 1998.

20. Mall S., Johnson WS. and Everett RA., Cyclic debonding of adhesively bonded composites, NASA Technical Memorandum 8577, November 1982.

21. Butkus LM., Environmental durability of adhesively bonded joints, Phd thesis, The Georgia Institute of Technology, available online at www.dtic.mil/dtic/tr/fulltext/u2/a330646.

22. Butkus LM., Valentin RV., Johnson WS., Evaluating Environmental Effects on Bonded Repair Systems Using Fracture Mechanics, Chapter 6, A. Baker, L. R. F. Rose and Jones R., Elsevier Applied Science Publishers, 2002. ISBN 0-08042699-9.

23. Zhao XL., Zhang L., State-of-the-art review on FRP strengthened steel structures, Engineering Structures, 29, 8, pp. 1808-1823, 2007.

24. Zhao XL., Al-Mahaidi R., Xiao ZG., Chen T., Gu XL, International Journal of Structural Stability and Dynamics, 14, 6, 2014, doi: 10.1142/S0219455414500187

25. Baker AA., Chester RJ., Davis MJ., Roberts JD. and Retchford JA., Reinforcement of the F-111 wing pivot fitting with a boron/epoxy doubler system materials engineering aspects, Composites. 24. 6. 1993, pp. 511-521.

26. Borrie D., Liu HB., Zhao XL., Singh Raman RK., Bai Y., Bond durability of fatigued CFRP-steel double-lap joints pre-exposed to marine environment, Composite Structures, 131, pp. 799-809, 2015.

27. Jones R. and Tamboli D., Implications of the lead crack philosophy and the role of short cracks in combat aircraft, Engineering Failure Analysis, 29, pp. 149-166, 2013. 
28. Jones R, Molent L., Barter S., Calculating crack growth from small discontinuities in 7050-T7451 under combat aircraft spectra, International Journal of Fatigue, 55, pp. 178-182, 2013.

29. Barter SA., Fatigue Cracking in Aluminium Alloy 7050-T7451 - Quantitative Fractographic Methods and Life Prediction, Phd Thesis, Department of Mechanical Engineering, Faculty of Engineering, Monash University, March 2007.

30. Burchill M., Walker K., Barter S., Wang $\mathrm{CH}_{\text {., }}$ Khadka A., Improvements to predicting fatigue crack growth rates in aluminium alloy (AA7050-T7451) loaded with a standard transport aircraft spectrum, in Recent Advances in Structural Integrity Analysis Proceedings of the International Congress (APCF/SIF-2014) , Sydney, pp. 132-136, 2015.

31. Baker AA., Callinan RJ., Davis MJ., Jones R. and Williams JG., Application of B.F.R.P. patching to Mirage III Aircraft, Theoretical and Applied Fracture Mechanics, 2, 1, pp. 116, 1984.

32. Jones R, Numerical analysis and design, Chapter 9, Bonded Repair of Aircraft Structure, A. Baker and Jones R., Martinus Nijhoff Publishers, The Hague, 1988. (Book).

33. Butkus LM., Gaskin JA., Greer JM., Jr., Guijt CM., Jacobs NJ., Kelly DF., Mazza JJ., Bonded Boron Patch Repair Evaluation: Final Report, USAFA-TR-2007-06, October 2007.

34. Jones R., Fatigue Crack Growth and Damage Tolerance, Fatigue and Fracture of Engineering Materials and Structures, 37, 5, pp. 463-483, 2014.

35. Jones R., Pu Huang, Peng D., (2016) Crack growth from naturally occurring material discontinuities under constant amplitude and operational loads, International Journal of Fatigue, 91 pp. 434-444.

36. Jones R., Peng D., Pu Huang, Singh RRK., Crack growth from naturally occurring material discontinuities in operational aircraft, Procedia Engineering, 101, pp. 227 - 234, 2015.

37. Barter S., Tamboli D. and Jones R., On the growth of cracks from small naturally occurring material discontinuities (etch pits) under a mini-twist spectrum, Proceedings 2015 Aircraft Structural Integrity Program (ASIP), At The Hyatt Regency, San Antonio, Texas, USA, 1st-3rd December, 2015, http://www.meetingdata.utcdayton.com/agenda/Agenda.asp?ID=asip201514114 766

38. Jones R., A scientific evaluation of the approximate 2D theories for composite repairs to cracked metallic components, Composite Structures, 87, 2, pp. 151-160, 2009.

39. Jones R., Barter SA., Molent L and Pitt S., Crack patching: an experimental evaluation of fatigue crack growth, Composite Structures, 67, 2, pp. 229-238, 2005.

40. Barter SA., Molent L, N. Goldsmith and Jones R., An experimental evaluation of fatigue crack growth, Journal Engineering Failure Analysis, 12, 1, pp. 99$128,2005$.

41. Molent L., Jones R., A Stress versus Crack Growth Rate Investigation (aka Stress - Cubed Rule), International Journal of Fatigue, 87, pp. 435-443, 2016.

42. Gallagher JP. and Molent L., The Equivalence of EPS and EIFS Based on the Same Crack Growth Life Data, International Journal of Fatigue, 80, pp. 103110, 2015.

43. Frost N.E., Dugdale D.S., The propagation of fatigue cracks in test specimens, Journal Mechanics and Physics of Solids, 6, pp 92-110, 1958.

44. Zhuang W., Molent L., Block-by-block approaches for spectrum fatigue crack growth prediction, Engineering Fracture Mechanics, 75, pp. 4933-4947, 2008. 
45. Fisher JW., Kulak GL., Smith IFC., A Fatigue Primer For Structural Engineers, National Steel Bridge Alliance, May 1988.

46. American Association of State Highway and Transportation Officials, AASHTO LRFD Bridge Design Specifications, SI Units, First Edition, Washington, D.C., 1994.

47. Main B SQNLDR. Structural Analysis Methodology - F/A-18, Issue 2 AI2, RAAF, Directorate General Technical Airworthiness, Dec 2007.

48. Ayling J., Bowler A., Brick G., and Ignjatovic M., Practical Application of Structural Repair Fatigue Life Determination on the AP-3C Orion Platform, Advanced Materials Research, Vols. 891-892, pp. 1065-1070,2014, Trans Tech Publications, Switzerland.

49. Jones R., Chen F., Pitt S., Paggi M., Carpinteri A., From NASGRO to fractals: Representing crack growth in metals, International Journal of Fatigue, 82, pp. 540-549, 2016.

50. Molent L., Spagnoli A., Carpinter A. and Jones R., Fractals and the Lead Crack Airframe Lifing Framework, Proceedings 21st European Conference on Fracture, ECF21, 20-24 June 2016, Catania, Italy.

51. Mandelbrot BB, Passoja DE, Paullay AJ., Fractal character of fracture surfaces of metals, Nature, 19, 308, pp. 721-722.

52. Bouchaud E., Scaling properties of cracks, J. Phys.: Condens. Matter, 9, pp. 4319-4344, 1997.

53. Mandelbrot BB., Fractal analysis and synthesis of fracture surface roughness and related forms of complexity and disorder, Int J. Fracture, 138, pp. 13-17, 2006.

54. Baker AA., Crack patching: experimental studies, practical applications, Chapter 6, Bonded Repair of Aircraft Structure, A. Baker and Jones R., Martinus Nijhoff Publishers, The Hague, 1988. (Book), pp 107- 173.

55. Baker AA., Boron epoxy patching efficiency studies, Chapter 13, Advances in the Bonded Composite Repair of Metallic Aircraft Structure, A. Baker, L. R. F. Rose and Jones R., Elsevier Applied Science Publishers, 2002. ISBN 0-08-042699-9.

56. Guijt CB., Verhoeven S., Greer JM., and van Galen RM., A new approach to manipulate thermal stresses in Bonded repairs, Proceedings 6th Joint FAA/DoD/NASA Conference on Aging Aircraft o September 16-19, 2002 , San Francisco, USA.

57. Guijt C. and Verhoeven S., C-5A Fuselage Crown Cracking, Chapter 31, Advances in the Bonded Composite Repair of Metallic Aircraft Structure, A. Baker, L. R. F. Rose and R. Jones, Elsevier Applied Science Publishers, 2002. ISBN 0-08-042699-9

58. Davis SL., DeGood K., Donohue N. and Goldberg D, (2013) The Fix We're In For: The State of Our Nation's Busiest Bridges, Transportation for America, http://t4america.org/docs/bridgereport2013/2013BridgeReport.pdf

59. Gosbell, T., and Meggs, R., 2002, West Gate Bridge approach spans FRP strengthening Melbourne, Australia. Proc., IABSE Symposium, Melbourne, Australia.

60. Hongbo Liu, Zhao XL., Al-Mahaid R., Boundary element analysis of CFRP reinforced steel plates, Composite Structures, 91, pp. 74-83, 2009.

61. Chao Wu, Zhao XL., Al-Mahaidi R., Mohammad R. E. and Wenhui D., Fatigue Tests of Cracked Steel Plates Strengthened with UHM CFRP Plates, Advances in Structural Engineering, 15, 10, pp. 1801-1815, 2012.

62. Liu, H.B., Al-Mahaidi, R. and Zhao, X.L., Experimental study of fatigue crack growth behaviour in adhesively reinforced steel structures, Composite Structures, 90, 1, pp. 12-20, 2009. 
63. Qian-Qian Yu, Zhao XL., Al-Mahaidi R., Xiao ZG., Chen T., Gu XL, Tests on Cracked Steel Plates with Di®erent Damage Levels Strengthened by CFRP Laminates, International Journal of Structural Stability and Dynamics, 14, 6 (2014) 1450018, DOI: 10.1142/S0219455414500187

64. Colombi P. and Fava G, Experimental study on the fatigue behaviour of cracked steel beams repaired with CFRP plates, Engineering Fracture Mechanics, available on line at: http://dx.doi.org/10.1016/i.engfracmech.2015.04.009

65. Wang HT.; Wu G.; and Jiang JB., Fatigue behavior of cracked steel plates strengthened with different CFRP systems and configurations, Journal of Composites for Construction, 20, 3, pp. 04015078-1 to 04015078-9, 2016.

66. Miedlar PC., Berens AP., Gunderson A., and Gallagher JP. (2003) Analysis and support initiative for structural technology (ASIST), AFRL-VA-WP-TR-20033002. 


\section{APPENDIX}

To illustrate how the RAAF approach could be used to estimate the effect of a composite repair on a steel bridge consider the crack growth data presented in Figure A1 where the crack length data, up to a length of approximately $9 \mathrm{~mm}$, was obtained via quantitative fractography. The critical crack length for this section was estimated to be approximately $165 \mathrm{~mm}$, see Figure A1. The measured crack growth history can be seen to exhibit a (near) linear relationship between the log of the crack length and the number of cycles ${ }^{12}$ and as such conforms to equation (3) with a value of $\varpi=0.1159$ so that up to a length of approximately $9 \mathrm{~mm}$, which corresponds to a life of approximately 55 years, crack growth can be represented by equation (A1)

$$
\mathrm{a}=\mathrm{a}_{0} \mathrm{e}^{(0.1159 \mathrm{~N})}
$$

where $\mathrm{N}$ is now the number of year and $\mathrm{a}_{0}(=0.0146 \mathrm{~mm})$ is the initial flaw-like size (for cracks that grow from small naturally occurring material discontinuities the term $\mathrm{a}_{0}$ is referred to as an EFIS or EPS ${ }^{13}$ [42]). As such the time to grow to its critical crack size can be estimated using equation to be approximately 80 years which yields a remaining life for this location of approximately 25 years. This information can be used to determine the inspection intervals required.

Since as per $[40,41,43,44,47,48]$ the value of $\varpi$ is proportional to the cube of the stress the value of after patching $\left(\varpi_{\text {patch }}\right)$ is related to its value prior to patching ( $\left.\varpi_{\text {unpatched }}\right)$ and the ratio of the change of stress due to patching, viz:

$$
\varpi \text { patched }=\varpi_{\text {unpatched }}\left(\Delta \sigma_{\text {patched }} / \Delta \sigma_{\text {unpatched }}\right)^{3}
$$

If we assume that we repair patch halves the stress field and noting that in this example of $\varpi_{\text {unpatched }}=0.1159$ we obtain

$$
\varpi \text { patched }=0.1159 / 8=0.0145
$$

Thus the equation representing the resultant post patch crack growth history becomes:

$$
\mathrm{a}=9+0.0146 \mathrm{e}^{(0.0 .0145 \mathrm{~N})}
$$

This curve is also shown in Figure A1 where it can be seen that the patch would dramatically increase the remaining life of the section.

As can be seen from the above example an important feature of this approach is that the precise nature of the load time history is not required.

\footnotetext{
${ }^{12}$ As such crack growth is exponential.

${ }^{13}$ The term EIFS stands for equivalent initial flaw size and the term EPS stands for equivalent pre-crack size. The EIFS concept is discussed in more detail in [42] and also in the USAF report [66].
} 